\title{
Self-management among Heart Failure Patients
}

\author{
Amal Samir Ahmed*, Wafaa Nour*
}

\begin{abstract}
The purpose of this study was to describe heart failure patient's abilities to manage their disease. A descriptive correlational design was used in this study. A convenient sample of 120 adult patients with heart failure was surveyed using Self-Management of Heart Failure Tool as well as, the New York Heart Association (NYHA) Functional Classification to measure their functional status. The findings of this study showed that sixty percent of patient's age ranged from 50 to less than 60 years. Men accounted for $66.7 \%$ of the patient population and $33.3 \%$ were women. Most participants were married. The study revealed that recognizing a change in signs and symptoms was positively correlated with both implementing and evaluating treatment with statistical significance. In addition the results showed the statistical significant differences between levels of patients' education and both implementing and evaluating treatment. Finally, statistically significant differences were found between functional status of patients and their ability to recognize change as well as evaluate treatment. Findings of this study highlight the need for using the self management heart failure tool in practice to direct the medical and nursing staff towards the specific problem area for each patient.
\end{abstract}

Keywords: Self management; Heart failure

\section{INTRODUCTION}

Heart failure (HF) is a syndrome in which the heart fails to pump adequately to meet the body's metabolic needs. There are a variety of factors that can contribute to the development of (HF), including: longstanding hypertension, coronary artery disease, diabetes, smoking, obesity, high cholesterol levels, valvular defects, and congenital heart disease. Heart failure is a major cause of morbidity, reduced quality of life, and increased health care costs. The number of persons who suffer from HF expected to increase as the population ages and more people survive cardiac disease.(1) Approximately 23 million people worldwide are affect with heart failure (HF),

*Lecturer, Medical Surgical Nursing Department, Faculty of Nursing-Alexandria University Egypt 
and 2 million new cases of HF are diagnosed each year worldwide. In contrast to other cardiovascular disorders that have actually declined during the past few decades, the incidence of heart failure is on the rise. Cardiovascular disease made up 16.7 million, or $29.2 \%$ of total global deaths according to World Health Report. ${ }^{(2)}$

Symptoms of HF are associated with declines in physical function and emotional well-being, as well as increased health care utilization. ${ }^{(1)}$ Recognition and treatment of symptoms are priorities of care for patients with chronic illnesses such as HF. (3) If people with heart failure are to be successful in self-management, they must monitor their symptoms routinely and be knowledgeable about which symptoms are important to address immediately, willing in trying therapeutic options, and capable of evaluating the effectiveness of those actions. ${ }^{(4,5)}$

In developed and developing countries $\mathrm{HF}$ is a prevalent worldwide health problem. As the syndrome advances, persons with HF begin a cycle of fluid retention, acute symptom exacerbation and hospitalization that is best prevented with vigilant self-management. ${ }^{(6,7)}$

Self management refers to the behaviors that patients use to maintain physiologic stability such as medication taking and the response to symptoms when they occur. (8) Self-management in the context of chronic disease management was conceptualized as consisting of 4 stages: (I) recognizing that a change in signs or symptoms is related to the illness, (II) evaluating the change (III) implementing a selected treatment strategy and (IV) evaluating the effectiveness of treatment. $(4,9,10)$

Effective management of chronic illness is complex and requires significant participation by patients and their families. Day-to-day disease self-management has multiple components include engaging in activities that promote physical and 
psychological health; interacting with health care providers and adherence to treatment recommendations; monitoring health status and making associated care decisions; and managing the impact of the illness on physical, psychological and social functioning. ${ }^{(11)}$ Any impediments to these processes may jeopardize successful disease management and thereby represent barriers to the self-management process. Therefore, the investigators of this study attempted to answer the following questions: (a) Can heart failure patients recognize the change in signs and symptoms related to HF? (b) Can heart failure patients evaluate the importance of signs and symptoms related to $\mathrm{HF}$ and the effectiveness of the treatment? (c) Is there a relationship between biosocial data of patients with heart failure and selfmanagement?

\section{Methodology}

A descriptive corelational design was used to achieve the aim of this study.

\section{Sample and setting}

This study was carried out at the outpatient units at Shark El Madina Hospital in Alexandria a tertiary level governmental hospital. A convenient sample of 120 adult patients diagnosed with heart failure was surveyed in the study. Patients were considered eligible to participate in the study if they met the following criteria:

- Age more than 18 years and less than 60 years

- They also had to have New York Heart Association Class I-IV symptom within the last 3 months.

- Had at least 2 symptoms.

- Being psychologically and physically willing to participate.

* Patients were excluded if they had hearing impairment or dementia.

\section{Tools}

Three tools were used in this study. Tool

1: Bio-socio demographic sheet. It includes data on patient age, sex, marital status, 
employment status, education, regular activities, smoking habit, dietary habit, comorbidities and drugs used.

Tool 2: The New York Heart Association (NYHA) Functional Classification of HF. It provides a simple way of classifying the extent of heart failure. It places patients in one of four categories based on how much they are limited during physical activity; the limitations/symptoms are in regards to normal breathing and varying degrees in shortness of breath, fatigue, palpitation and or anginal pain. Functional status was measured by using the following classification:

Class I: Patients with no limitation of activities; they suffer no symptoms from ordinary activities.

Class II: Patients with slight, mild limitation of activity; they suffer symptoms from ordinary activity.

Class III: Patients with marked limitation of activity; they suffer symptoms from less than ordinary activity and they are comfortable only at rest.

Class IV: Patients who should be at complete rest; any physical activity brings on discomfort and symptoms occur at rest.

Tool 3: Self- Management of Heart Failure tool. It was developed by Riegel et al. (2000). It assesses patients' ability to manage their heart disease. It includes 4 stages. The first stage, recognizing a change in signs or symptoms, involves the patient's recognition that a change from baseline health status has occurred and that change is related to heart failure. The Patients were asked questions designed to determine if they could recognize changes in their signs and symptoms. Eight common symptoms of heart failure are used to prompt patient responses; shortness of breathing, ankle swelling, fatigue, palpitation, sudden weight gain, difficult breathing while sleeping, coughing, and dizziness. A 4- point Likert scale ranging from (4) very quickly recognized to 
(1) not recognized were used for each sign or symptom.

The second stage, evaluating the change, involves a cognitive process that occurs as the patient attempts to distinguish between important and unimportant changes in health status. At this stage the patients were asked to indicate the importance of each heart failure symptom they reported on a 3-point Likert-type scale ranging from" very important", " some what important"; or "not important". The score assigned ranged from 3 to 1 with 3 for very important response and 1 for not important choice.

The third stage, implementing a selected treatment strategy, is defined as action or behavior undertaken by the patient in response to the previous stages. The Patients were asked to describe what they did to treat each of the changes in signs and symptoms they reported.

The fourth and final stage, evaluating the effectiveness of the treatment implemented. The Patients were asked to evaluate the effectiveness of each chosen treatment implemented to determine if they could evaluate the treatment. Patients' responses were checked on a 3 choices ranging from effective; not effective; or unsure. When patients chose effective or not effective they were rated as able to evaluate the treatment, " unsure" response indicated an inability to evaluate the treatment.

Content validity of Self- Management of Heart Failure tool was demonstrated adequately through a previous research study (Riegel et al. 2000). Reliability of the tool showed internal consistency scores of the 4 subscales of the Self- Management of Heart Failure tool ranging from 0.79 to 0.92. In the current study, the internal consistency of the 4 subscales ranged from 0.81 to 0.90 indicating that the tool was reliable. Translation of the tools was done using the back- translation method for each tool. The 3 tools were piloted with a group 
of 10 patients to examine clarity and feasibility of the tools.

\section{Ethical considerations}

The participants' rights were protected by explaining to the participants the purpose and significance of the study and their role in the study. Participants were reassured that their responses will be kept anonymous, and no remarks will be made to identify the client's identity. The client was informed that his/her participation in the study is voluntarily and he/ she can withdraw at any time, and that his/her withdrawal will not affect the care he/she receives at the hospital.

\section{METHODS}

Research committee at University of Alexandria approved the study proposal, methodology, and instruments. In addition, required permission for data collection was obtained from the director of the hospital. Patients who agreed to participate in the study and met the inclusion criteria were asked to sign a written informed consent form. Content validity was checked by group of experts in the field of nursing. Data were collected by researchers through individualized interview with patient in the outpatient clinic. The patients were given the option of completing the tools with or without assistance, and the illiterate patients chose to have the researchers read the questionnaires to them and record their responses. Furthermore, the patients were given the chance to ask any question related to the study. Data collection was conducted over a period of 3 months from the beginning of May to the end of July 2005.

\section{Data analysis}

Data were analyzed using the statistical package for social sciences version 9 (SPSS) computer program. Descriptive and inferential statistics were performed on the self- management scale as well as functional status and bio demographic data. To determine association between patient's self management ability and their 
bio socio-demographic data, one way the study subjects were diabetic. Majority analysis of variance test (ANOVA) was of the patients $(67.5 \%$ ) didn't report a used. The Newman-Keuls method is a family history of heart failure.

post-hoc test that was used for Recognition of change in signs and comparisons after the performed F-test in case of its significance. Values of $p<0.05$ were considered significant.

\section{RESULTS}

Bio-socio-demographic description of participants

Table 1: Shows the baseline demographic and clinical characteristics of the study subjects. The study revealed that sixty percent of the patients ranged their age from 50 years to less than 60 years and $66.7 \%$ were men. Seventy percent of the patients were married and more than half (55\%) were employed. Functional class of the sample was distributed as follows: $10.8 \%$ were class I, $35 \%$ class II, $29.2 \%$ class III and $25 \%$ class IV. More than one third of the patients $(41.7 \%)$ admitted previously to different hospitals because of their heart disease. In addition $33.3 \%$ of

\section{symptoms}

Figure 1 Shows the patient's recognition of changes in signs and symptoms related to heart failure.

Shortness of breath, difficult breathing while sleeping, and palpitation were quickly recognized as signs and symptoms related to heart failure by $67.5 \%, 45.8 \%$, and $37.5 \%$ of the patients respectively. Where as, dizziness, ankle swelling, and sudden weight gain were not recognized as signs and symptoms related to heart failure by $39.2 \%, 36.7 \%$, and $30.8 \%$ of the patients respectively.

\section{Evaluating the changes}

Table 2: Shows patient's perceptions of the importance of heart failure signs and symptoms. Seventy seven point five percent and fifty two point five percent of the study subjects rated shortness of 
breath at rest and while sleeping as important heart failure symptoms. Whereas only $15 \%$ rated difficulty climbing stairs as important heart failure symptom. More than half of the patients $(55.8 \%)$ rated the inability to do normal activities of daily living as having only some importance. Half of the patients didn't consider sudden weight gain as an important heart failure sign. In addition, $41.7 \%$, and $35 \%$ of the study subjects reported that dizziness, ankle swelling not important heart failure signs and symptoms.

\section{Implementing of treatment strategy}

The study revealed that more than half of the study subjects increased prescribed diuretic dose to manage ankle swelling whereas only $14 \%$ and $20 \%$ of the patients reported that they decreased salt in diet and fluid intake to manage ankle swelling. Majority of the patients (75\%) reported that they were lying in semi setting position to manage difficulty of breathing while sleeping. In addition, most of them (80\% and $77 \%$ ) took period of rest to manage dizziness and shortness of breathing during activities of daily living respectively. The study also revealed that more than two third of the patients (68\%) took no action in response to a sudden weight gain.

\section{Evaluating the treatment strategy}

Table 3: Shows patient's evaluation of the effectiveness of the treatment. Majority of the patients $(79.2 \%$ and $73.3 \%)$ reported that taking diuretics and decrease activity were effective to manage their difficulty of breathing and ankle swelling respectively. In addition, more than half of the patients (55\%and $58.3 \%$ ) did not try to reduce salt or fluid intake to manage fluid retention. On the other hand, only $5 \%$ of the patients reported that reduced fluid intake was effective to manage fluid retention. The study also revealed that approximately, half of the study subjects reported that visiting the doctor for guidance was effective to manage their signs and symptoms related to heart failure. 
Relationship between the bio- social data of the patients with heart failure and the self-management subscales

Table 4: Shows the relationship between the bio-social data of the patients with heart failure and the self-management subscales. The results revealed that patients who have a university degree obtained higher mean scores in relation to implementing and evaluating treatment than those who only were able to read and write. In addition, the differences were statistically significant $(P=0.023 \& \quad P=0.00$ respectively). Moreover, the results indicated that there were statistical significant differences between function status classification and both recognizing change and evaluating treatment $(P=0.037$ $\& P=0.016)$ respectively.

The findings also revealed that evaluating treatment were significantly higher for those who were between 30 and 40 years of age with a mean of (2.62) in comparison to those patients between 50 and 60 years of age with a mean of (2.22) $(P=0.037)$. In relation to living status, the results indicated that implementing treatment was significantly higher in patients who were living with others with a mean of (6.89) while the mean of those who were living alone was (6.406) $(P=$ 0.030).

\section{Correlations among the self- management subscales}

Table 5: Shows the correlations among the self-management subscales of patients with heart failure. This table revealed that recognizing a change was positively correlated with both implementing and evaluating treatment $(r \quad 0.291$ and $r \quad 0.471$ respectively) with statistical significance (where $\mathrm{p}$ were $0.001,0.000$ ) respectively. In relation to implementing treatment, it was positively correlated with evaluating treatment $(r=0.345)$. This correlation was highly statistically significant $(p=0.000)$. 
Table 1: Demographic and Clinical Characteristics of Heart Failure Patients

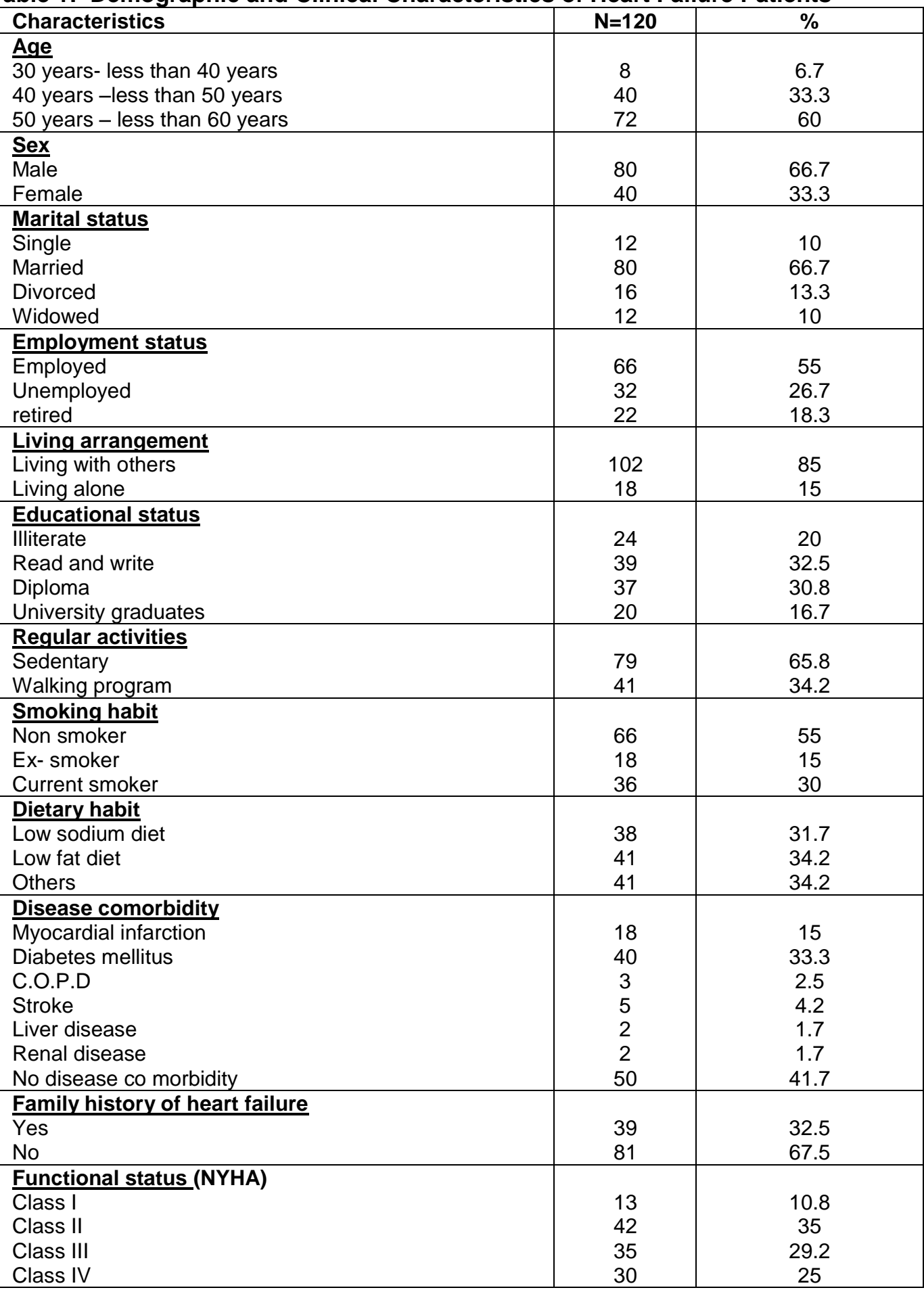




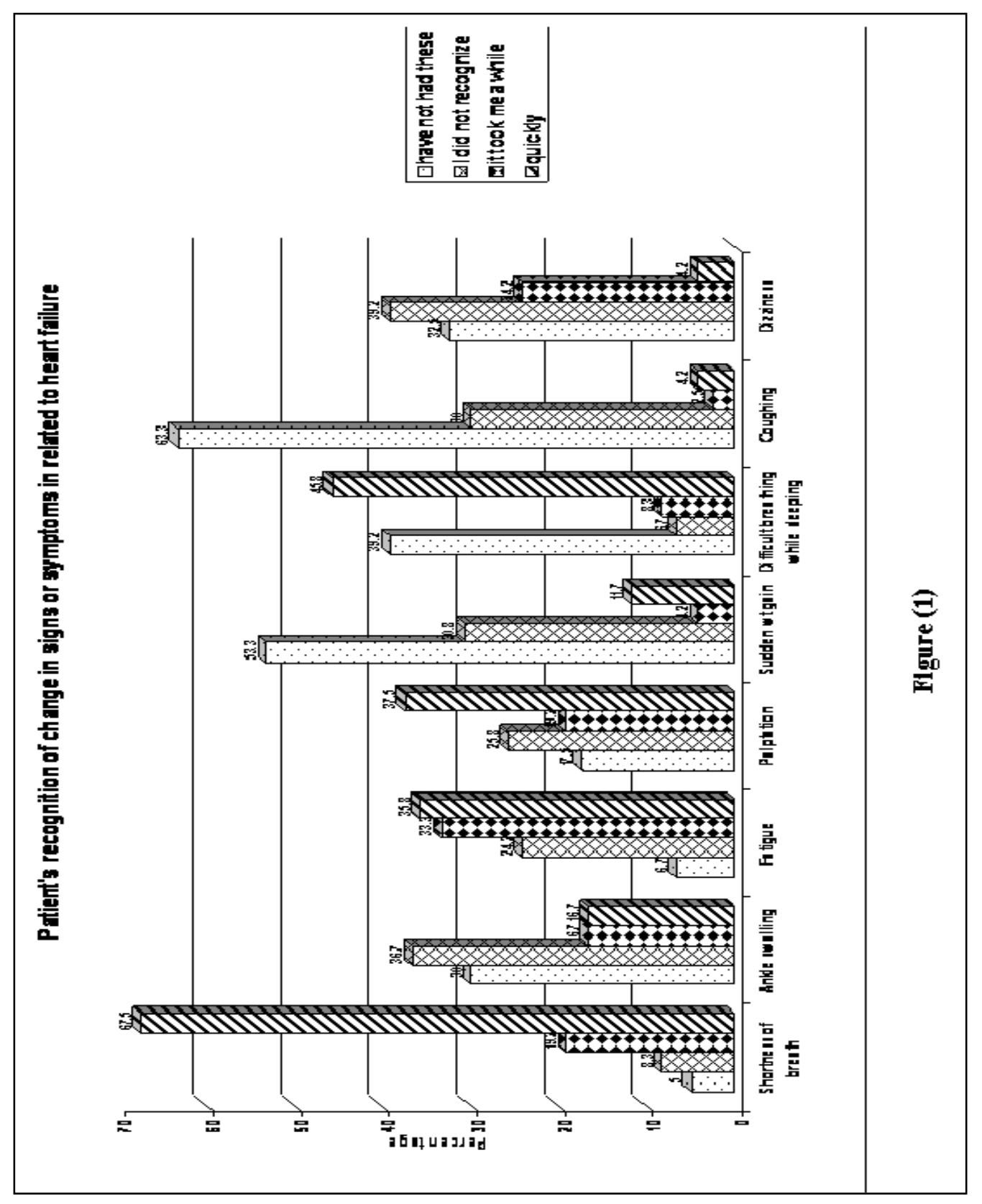


Table 2: Patients' Perceptions of the Importance of Heart Failure Signs \& Symptoms

\begin{tabular}{|c|c|c|c|c|c|c|}
\hline \multirow{3}{*}{ Signs and symptoms } & \multicolumn{6}{|c|}{ Evaluating the change } \\
\hline & \multicolumn{2}{|c|}{ Important } & \multicolumn{2}{|c|}{$\begin{array}{l}\text { Somewhat } \\
\text { important }\end{array}$} & \multicolumn{2}{|c|}{$\begin{array}{c}\text { Not } \\
\text { important }\end{array}$} \\
\hline & $\mathrm{N}$ & $\%$ & $\mathrm{~N}$ & $\%$ & $\mathrm{~N}$ & $\%$ \\
\hline Shortness of breath at rest & 93 & 77.5 & 25 & 20.8 & 2 & 1.7 \\
\hline Difficulty of breathing while sleeping & 63 & 52.5 & 49 & 40.8 & 8 & 6.7 \\
\hline Coughing & 56 & 46.7 & 24 & 20 & 40 & 33.3 \\
\hline Sudden weight gain & 53 & 44.2 & 7 & 5.8 & 60 & 50 \\
\hline Ankle swelling & 52 & 43.3 & 26 & 21.7 & 42 & 35 \\
\hline Dizziness & 48 & 40 & 22 & 18.3 & 50 & 41.7 \\
\hline Palpitation & 47 & 39.2 & 59 & 49.2 & 14 & 11.7 \\
\hline Difficulty of sleeping & 47 & 39.2 & 48 & 40 & 25 & 20.8 \\
\hline Shortness of breath during activities & 44 & 36.7 & 73 & 60.8 & 3 & 2.5 \\
\hline Inability to do normal activities of daily living & 30 & 25 & 67 & 55.8 & 23 & 19.2 \\
\hline Decrease in energy level & 29 & 24.2 & 83 & 69.2 & 8 & 6.7 \\
\hline Difficulty of walking around or climbing stairs & 18 & 15 & 66 & 55 & 36 & 30 \\
\hline
\end{tabular}

Table 3: Patients' Evaluation of the Effectiveness of Treatment

\begin{tabular}{|l|c|c|c|c|c|c|}
\hline \multirow{2}{*}{ Treatment } & \multicolumn{6}{|c|}{ Evaluating the treatment } \\
\cline { 2 - 7 } & \multicolumn{2}{|c|}{ Sure } & \multicolumn{2}{c|}{ Not sure } & \multicolumn{2}{c|}{ I didn't try anything } \\
\cline { 2 - 7 } & $\mathbf{N}$ & $\%$ & $\mathbf{N}$ & $\%$ & $\mathbf{N}$ & $\%$ \\
\hline Take water pills & 95 & 79.2 & 13 & 10.8 & 12 & 10 \\
\hline Take period of rest & 92 & 76.7 & 16 & 13.3 & 12 & 10 \\
\hline Decrease activity & 88 & 73.3 & 21 & 17.5 & 11 & 9.2 \\
\hline Take medication & 88 & 73.3 & 22 & 18.3 & 10 & 8.3 \\
\hline Used extra pillow & 69 & 57.5 & 11 & 9.2 & 40 & 33.3 \\
\hline Visit the doctor for guidance & 62 & 51.7 & 36 & 30 & 22 & 18.3 \\
\hline Reduce the salt intake & 30 & 25 & 24 & 20 & 66 & 55 \\
\hline Sleep in recliner & 27 & 22.5 & 19 & 15.8 & 74 & 61.7 \\
\hline Reduce the fluid intake & 6 & 5 & 44 & 36.7 & 70 & 58.3 \\
\hline
\end{tabular}


Table 4: Relationship between Bio- social Data of Patients with Heart Failure

\& Self-management Subscales

\begin{tabular}{|c|c|c|c|c|c|}
\hline & & $\begin{array}{c}\text { Recognizing } \\
\text { change }\end{array}$ & $\begin{array}{c}\text { Evaluating } \\
\text { change }\end{array}$ & $\begin{array}{c}\text { Implementing } \\
\text { treatment }\end{array}$ & $\begin{array}{c}\text { Evaluating } \\
\text { treatment }\end{array}$ \\
\hline \multicolumn{6}{|c|}{ Educational Status } \\
\hline illiterate & Mean(SD) & $2.157(0.633)$ & $2.487(0.549)$ & $6.699(0.974)$ & $2.3486(0.537)$ \\
\hline read and write & Mean(SD) & $2.353(0.411)$ & $2.819(0.555)$ & $6.029(1.332)$ & $2.040(0.408)$ \\
\hline diploma & Mean(SD) & $2.495(0.450)$ & $2.571(0.875)$ & $6.745(1.539)$ & $2.484(0.539)$ \\
\hline university graduates & Mean(SD) & $2.507(0.695)$ & $2.761(0.483)$ & $7.067(0.882)$ & $2.641(0.452)$ \\
\hline Sig & & 0.05 & 0.10 & $0.023^{*}$ & $0.00^{*}$ \\
\hline \multicolumn{6}{|c|}{ Sex } \\
\hline Male & Mean(SD) & $2.319(0.550)$ & $2.626(0.638)$ & $6.732(1.167)$ & $2.303(0.535)$ \\
\hline Female & Mean(SD) & $2.611(0.581)$ & $2.956(0.512)$ & $6.75(1.315)$ & $2.494(0.397)$ \\
\hline Sig & & 0.129 & 0.135 & 0.965 & 0.299 \\
\hline \multicolumn{6}{|c|}{ Functional Status } \\
\hline class I & Mean(SD) & $2.25(0.923)$ & $2.611(0.455)$ & $6.698(1.927)$ & $2.056(0.475)$ \\
\hline class II & Mean(SD) & $2.174(0.532)$ & $2.461(0.748)$ & $6.721(1.166)$ & $2.382(0.537)$ \\
\hline class III & Mean(SD) & $2.525(0.378)$ & $2.771(0.619)$ & $6.411(0.916)$ & $2.419(0.419)$ \\
\hline class IV & Mean(SD) & $2.4(0.524)$ & $2.8(0.464)$ & $7.142(0.991)$ & $2.444(0.714)$ \\
\hline Sig & & $0.037^{*}$ & 0.075 & 0.096 & $0.016^{*}$ \\
\hline \multicolumn{6}{|c|}{ Age (years) } \\
\hline $30-40$ & Mean(SD) & $2.703(0.327)$ & $2.3(0.500)$ & $6.141(1.270)$ & $2.625(0.385)$ \\
\hline $40-50$ & Mean(SD) & $2.384(0.580)$ & $2.788(0.697)$ & $6.484(1.076)$ & $2.422(0.514)$ \\
\hline $50-60$ & Mean(SD) & $2.276(0.549)$ & $2.614(0.596)$ & $6.938(1.180)$ & $2.225(0.529)$ \\
\hline Sig & & 0.091 & 0.101 & 0.05 & $0.037^{*}$ \\
\hline \multicolumn{6}{|c|}{ Living Status } \\
\hline livina alone & Mean(SD) & $2.253(0.503)$ & $2.627(0.635)$ & $6.406(1.235)$ & $2.290(0.512)$ \\
\hline livina with others & Mean(SD) & $2.516(0.617)$ & $2.698(0.637)$ & $6.897(1.112)$ & $2.372(0.559)$ \\
\hline Sig & & 0.014 & 0.566 & $0.030^{*}$ & 0.424 \\
\hline
\end{tabular}

* Statistically significant at $p<0.05$ 
Table 5 Correlation among the Self-management Subscales of Patients with Heart Failure

\begin{tabular}{|l|c|c|c|c|c|}
\hline \multicolumn{2}{|c|}{} & $\begin{array}{c}\text { Recognizing } \\
\text { change }\end{array}$ & $\begin{array}{c}\text { Evaluating } \\
\text { change }\end{array}$ & $\begin{array}{c}\text { Implementing } \\
\text { treatment }\end{array}$ & $\begin{array}{c}\text { Evaluating } \\
\text { treatment }\end{array}$ \\
\hline $\begin{array}{l}\text { Recognizing } \\
\text { change }\end{array}$ & $\mathrm{r}$ & & -0.061 & $0.291^{*}$ & $0.471^{*}$ \\
\cline { 2 - 6 } Evaluating change & $\mathrm{P}$ & & 0.510 & 0.001 & 0.000 \\
\hline & $\mathrm{r}$ & & & -0.178 & -0.071 \\
\hline $\begin{array}{l}\text { Implementing } \\
\text { treatment }\end{array}$ & $\mathrm{P}$ & & & 0.052 & 0.442 \\
\hline & $\mathrm{P}$ & & & & $0.345^{*}$ \\
\hline $\begin{array}{l}\text { Evaluating } \\
\text { treatment }\end{array}$ & $\mathrm{r}$ & & & & 0.000 \\
\hline
\end{tabular}

* Statistically significant at $p<0.05$

\section{DISCUSSION}

Heart failure (HF) is a chronic illness that contributes to disability and death. Self-management and decision making are essential skills for patients striving to manage their HF. One way to avoid hospitalizations and promote positive health outcomes among HF patients is to ensure that the amount and quality of selfmanagement used is appropriate to their situation. $(4,11)$ The study revealed that recognizing a change in signs and symptoms was positively correlated with both implementing and evaluating treatment with statistical significance. The interpretation could be that the patients may recognize a change and skip stage 2 (i.e., evaluate the change), immediately implementing a treatment strategy because of past experience with a particular symptom.

Shortness of breath was recognized as signs related to heart failure by majority of the patients, while dizziness, ankle swelling, and sudden weight gain were not recognized as signs and symptoms related to heart failure by approximately one third of the patients. This could be referred to the signs and symptoms of heart failure are 
extremely difficult for patients to recognize.

The patients may not experience the same symptom consistently enough to observe it, relate it to precipitating behaviors, trial relief strategies, and evaluate those attempts. Moreover, many of these patients were dealing with comorbid conditions, which complicated their attempts to manage their heart failure. This is consistent with another study which showed that patients fail to recognize problems, forget treatments, and delay decision making. ${ }^{(4)}$ Other studies indicated that most patients had trouble in determining if a particular symptom such as faintness was related to HF, perhaps because of their other diagnosis. $(11,12)$

Once they recognized the symptoms, these patients also had difficulty in interpreting them accurately or identifying them as warning signs. Half of the patients did not consider sudden weight gain as important heart failure sign. In addition, more than one third of the study subjects reported that dizziness, ankle swelling not important heart failure signs and symptoms. The interpretation could be that there are many factors influencing patients' abilities to recognize and evaluate their symptoms which might be the high rate of multiple symptoms, lack of knowledge, misconceptions and ignoring. In this respect, Riegel and Carlson 2002(12) reported that method of adapting with disease included ignoring the problem and some patients ignoring their symptoms and refusing to think about it- Furthermore, other previous researches reveled that patients may miss the significance of their symptoms and attribute them to normal aging believing "I am tired because I am old". (13,14)

When the patients were asked to describe what they did to treat each of the changes in signs and symptoms, it was evident from the responses that patients were trying a variety of self-management measures, but the specific treatment used 
did not necessarily match the symptom. The study revealed that the minority of the patients reported that they decreased salt in diet and fluid intake to manage ankle swelling. In addition, more than two third of the patients took no action in response to a sudden weight gain. The interpretation could be that if patients are unable to recognize a change in their symptoms, it is unrealistic to expect them to act on those symptoms and the patient may passed through the first few stages and still not taking action for various reasons. He or she may lack knowledge about what to do and make a judgment that the costs of the action outweigh the benefits or taking an irrelevant action such as restriction of fluid intake. $(15,16,17,18)$ This is in agreement with a previous study which reported that patient may fail to understand the importance of the change or believe that no effective strategy is available. Moreover, the author illustrated that the decision itself is an important part of self-management. (4)
Riegel et al.2000 (4) reported that Patients were asked what influenced their decision to take action when they had symptoms. Although the patients had difficulty articulating the process they used to come to a decision, most of patients would do something if the symptoms became severe. That is, they were making their decisions regarding self-management based on the severity, not the importance, of the signs and symptoms. On the other hand, other studies mentioned that patients apparently know what to do but choose not to perform self-care for some reason. Poor adherence to recommended treatment and to behavior modification are common in individuals with HF.(19) In relation to actions to manage difficulty of breathing, majority of the patients reported that they were lying in semi setting position and were using more than one pillow to manage difficulty of breathing while sleeping. In addition, most of them took period of rest to manage dizziness and shortness of breathing 
during activities of daily living. This is in agreement with other studies which confirmed that some of the strategies were used to manage several symptoms. Changing the level of physical activity was a common management strategy for a variety-of symptoms. For example, in response to shortness of breath, and fatigue patients reported waiting for few activities, or staying quiet. (20,21) Other studies reported that patients used progressive minutes to perform an activity, completing activities at a slower pace, resting between muscle relaxation exercises for shortness of breath. (8) Treatment effectiveness, is the last component of self management. It involved evaluation of the helpfulness of selected treatment. The results of this study revealed that the majority of patients rated decreasing activities and taking period of rest for fatigue and shortness of breath as effective treatment. On the other hand small percentage of patients rated decreasing salt and fluid intake for sudden weight gain and ankle swelling as effective treatment. The interpretation may be that more than half of the patients didn't try to reduce salt or fluid intake. This is consistent with a study that shows if no remedy was tried, patients are unable to evaluate treatment effectiveness. ${ }^{(22,23)}$

Self-management with HF is clearly challenging. The difficulty patients have in identifying their HF symptoms provides direction to health care professionals for teaching patients. Educational interventions need to stress the importance of self- monitoring and teach specific selfmanagement strategies for particular symptoms. The information from this study, we can help patients to become and remain motivated to comply with regimen, to prioritize the symptoms and treatment, to ask for help if symptoms worsened, and to adapt their activities. Finally, the study findings indicated that HF self management behaviors are essential 
behaviors for patients with $\mathrm{HF}$ to master and achieve the best possible health outcomes. Furthermore, use of the selfmanagement of $\mathrm{HF}$ tool in practice can help the medical and nursing staff to assess barriers and facilitators to heart failure self-management that may contribute to patient motivation.

\section{CONCLUSIONS}

It could be concluded that, the study participants were able to quickly recognize some signs and symptoms of heart failure including shortness of breath, palpitation and difficult sleeping at night but they were unable to evaluate other important signs and symptoms and implement the appropriate treatment. A clinical measure of self-management in heart failure is greatly needed for medical and nursing to assess and improve self management abilities of patients particularly those with poor literacy and living alone.

\section{RECOMMENDATIONS}

The findings of this study could be used by medical and nursing staff to evaluate deficiencies in the selfmanagement process and to identify specific patient education and counseling needs. Educating patients about heart failure treatment and consequences may be expected to increase self-management abilities and improve self-management behavior. These can give patients more control of their daily lives. In addition, these are expected to help patients deal better with their social function and as a result they may have an influence on their psychological state. To support patient selfmanagement, the medical and nursing staff should define with the patients the goals for managing their heart failure. Moreover, they must discuss the importance of selfmanagement for the optimal management of heart failure with the patients and work with the patient on the specifics of the plan including monitoring of target symptoms and signs and use of medications. Finally, nurses will provide resource information 
and patient reminders, including when to

return for appointments.

\section{REFERENCES}

1. Hagenhoff B, Feutz C, Conn V. et al. Patient education needs as reported by congestive heart failure patients and their nurses. Journal of Advanced Nursing 1994;

19:685-690

2. Tatsumi E. Domestic and foreign trends in the prevalence of heart failure and the necessity of nextgeneration artificial hearts: a survey by the Working Group on Establishment of Assessment Guidelines for NextGeneration Artificial Heart Systems. The International Journal of Artificial Organs 2007; 10(4):187-194.

3. Bennett S, Cordes D, Westmoreland G. et al. Self-care strategies for symptom management in patients with chronic heart failure. Nursing Research 2002; 49 (3):139-145.

4. Riegel B, Carlson B., Glaser D. Development and testing of a clinical tool measuring self- management of heart failure. Heart \& Lung 2000; 29 (1):4-15.

5. Dewalt D, Malone R, Bryant M. et al. A heart failure self- management program for patient of all literacy levels: A randomized controlled trial. BMC Health Services Research 2006; 6(4): 102-112.

6. Welsh JD, Schooler MP. et al. Characteristics and treatment of patients with heart failure in the emergency department. Journal of Emergency Nursing 2002; 28:126131.

7. Riegel B, Dickson V, Goldberg L. et al. Factors associated with the development of expertise in heart failure self -care .Nursing Research
2007; 56 (4):235-243.

8. Martje HL,Tiny J. Compliance in Heart Failure Patients: The Importance of Knowledge and Beliefs. European Heart Journal 2005; 17:1-7.

9. Carlson B, Riegel B, Moser D. Selfcare abilities of patients with heart failure. Heart and Lung 2001; 30(50):315-319.

10. Frank D, Karyn H. Self- management decision influences in heart failure. Clinical Nursing Research 2003; 12(1): 69-84.

11. Elizabeth A, John F. Descriptions of barriers to self-care by persons with co morbid chronic diseases. Annals of Family Medicine 2003; 1:15-21

12. Riegel B, Carlson B. Facilitators and barriers to heart failure self- care. Patient Education and Counseling 2002; 46(4): 278-295.

13. Friedman M. Older adults' symptoms and their duration before hospitalization for heart failure. Heart\& Lung 1997;26:169-176.

14. Evangelista LS. Treatment seeking delays in heart failure patients. The Journal of Heart and Lung Transplantation 2000; 19(10):932-938.

15. Artinian N, Magnan M, Christian W .et al. What do patients know about their heart failure? Applied Nursing Research 2002; 15(4):200-208.

16. Donovan JL, Blake DR. Patient non compliance: derviance or reasoned decision making? Social Science and Medicine 1992; 34(5):507-513.

17. Clark J, Lan V. Heart failure patient learning needs after hospital discharge. Applied Nursing Research 2004; 17(3): 150-157.

18. Riegel B, Carlson B, Moser D.et al. Psychometric testing of the self-care of heart failure index. Journal of Cardiac Failure 2004; 4: 350-360.

19. Lewis C, Stephens B. Improving 
palliative care provision for patients with heart failure. British Journal of Nursing 2005; 14(10):563-567.

20. Jaarsma $T$, Halfen $R$, Tan $F$. et al. Self-care and quality of life in patients with advanced heart failure: The effect of a supportive educational intervention. Heart \& Lung 2000; 29 (5):319-330.

21. Riedinger $M$, Dracup $K$, Brecht $M$. et al. Quality of life in patients with heart failure: Do gender differences exist?
Heart \&Lung 2001; 30(2): 105-116.

22. Monane M, Bohn RL,Gurwitz JH. et al. Noncompliance with congestive heart failure therapy in the elderly Archives of Internal Medicine 1994; 154:433-437.

23. Riegel B, Dickson V, Hoke $L$ et al. A motivational counseling approach to improving heart failure self-care. Journal of Cardiovascular Nursing 2006; 21 (3):232-241. 